\title{
EDITORIAL
}

\section{Anticonvulsant drugs and mental symptoms: a review}

\author{
HISTORICAL INTRODUCTION
}

Deterioration of the mental state in epilepsy has been commented on since antiquity. Temkin (1971) quotes Aretaeus as saying that epileptics were 'languid, spiritless, stupid, unsociable... [and] slow to learn from torpidity of the understanding and the senses. . . Nearer to the present time Gowers (1885) comments 'the mental state of epileptics frequently presents deterioration. . . In its slighter forms there is merely defective memory... in more severe degree there is greater imperfection of intellectual power.... Upholding the view that seems to have been predominant in the latter part of the last century he attributed this deterioration to the underlying epilepsy. Other authors supported this view quoting, for example, studies which showed that institutionalized epileptics had low IQ's (Fox, 1924). However, a distinct paradox remained. History has many examples of highly intelligent epileptics who did not deteriorate with their illness - Pliny, Caligula, Petrarch, Caesar, Napoleon and Handel to name but a few. Guerrant et al. (1962) have reviewed the changing concepts of the nature and frequency of mental changes in epileptics in the last century, culminating in the present view that the majority of patients have normal mental states and in those in whom deterioration occurs many different factors may operate, although the relative importance of each of these (underlying brain disease, the effects of seizures, genetic factors, psychosocial factors and drugs) is still a matter of uncertainty and disagreement. Guerrant et al. comment that a minority of authors have occasionally implicated a deleterious effect of anticonvulsant drugs, but generally this has been doubted, apart from well-recognized sedative effects, and not submitted to investigation. More recently, with increasing recognition of some of the chronic metabolic and neuropathological effects of anticonvulsant therapy (Reynolds, 1975a), and the development of techniques for measuring serum anticonvulsant levels (Woodbury et al., 1972), more serious attention is being directed at the possible role of such therapy in the precipitation of mental symptoms. In this paper it is our intention to critically review the scattered literature on this subject, a task which, to our knowledge, has not previously been undertaken.

\section{THE STUDIES OF LENNOX}

Lennox (1942) looked specifically at the problem of mental deterioration and epilepsy and his studies represent the first systematic attempt to investigate the role that anticonvulsants play in this process. In a paper entitled 'Brain injury, drugs and environment as causes of mental decay in epilepsy', he tried to assess what drugs had been used in a series of 1245 epileptic patients, and what effects these drugs had on their seizures and mental state. He examined five possible causes for mental deterioration: (1) heredity; (2) brain injury antedating the onset of seizures; (3) psychological handicaps; (4) epilepsy itself; and finally (5) drugs. He estimated that anticonvulsant drugs were incriminated in this process in $15 \%$ of his cases and comments that 'many physicians in attempting to extinguish seizures only succeed in drowning the finer intellectual processes of their patients. . . The intelligent and individualistic use of anticonvulsant drugs should not and does not impair the patient's mind.' At the time Lennox undertook his study, bromides, phenobarbitone and a variety of proprietary remedies were the only drugs available for the treatment of epilepsy, and his findings indicated that phenobarbitone was the most effective anticonvulsant, and that it impaired mental processes the least.

Writing on the same subject 18 years later, Lennox still implicated the same five causes but now held that anticonvulsants were only responsible for approximately $5 \%$ of the cases of mental deterioration which he encountered (Lennox \& Lennox, 1960). 
TABLE 1

SUMMARY OF STUDIES OF PSYCHOLOGICAL FUNCTION IN RELATION TO ANTICONVULSANT DRUGS

\begin{tabular}{|c|c|c|c|c|c|c|c|c|}
\hline Author & Date & $n$ & Subjects & $\begin{array}{l}\text { Con- } \\
\text { trol }\end{array}$ & $\begin{array}{l}\text { Duration } \\
\text { of study }\end{array}$ & Drugs & Serum levels & $\begin{array}{l}\text { Effect on } \\
\text { mental state }\end{array}$ \\
\hline $\begin{array}{l}\text { Somerfeld-Ziskind } \\
\& \text { Ziskind }\end{array}$ & 1940 & 100 & Ep & Yes & 2 years & Phenobarbitone & - & None \\
\hline Loveland et al. & 1957 & 26 & Ep & Yes & 3 months & $\begin{array}{l}\text { Phenobarbitone } \\
\text { D.P.H. } \\
\text { Primidone }\end{array}$ & - & None \\
\hline Royo \& Martin & 1959 & 3 & Ep & No & Variable & $\begin{array}{l}\text { Phenobarbitone } \\
\text { D.P.H. } \\
\text { Primidone } \\
\text { Mesantoin }\end{array}$ & - & Impaired \\
\hline Chaudhry \& Pond & 1961 & 28 & Ep & Yes & - & $\begin{array}{l}\text { Phenobarbitone } \\
\text { D.P.H. } \\
\text { Primidone }\end{array}$ & - & None \\
\hline Wapner et al. & 1962 & 36 & Ep & Yes & 6 weeks & Phenobarbitone & - & None \\
\hline Booker et al. & 1967 & 17 & Normal & Yes & 6 days & D.P.H. & - & None \\
\hline Guey et al. & 1967 & 25 & Ep & No & $\begin{array}{l}\text { Average } 7 \\
\text { months }\end{array}$ & Ethosuximide & - & Impaired \\
\hline Hutt et al. & 1968 & 4 & Normal & Yes & 1 month & Phenobarbitone & 'Therapeutic' & Impaired \\
\hline Rosen & 1968 & 20 & Ep & No & - & D.P.H. & $\cdots$ & $\begin{array}{l}\text { Improved on with- } \\
\text { drawing medication }\end{array}$ \\
\hline $\begin{array}{l}\text { Tchicaloff \& } \\
\text { Gaillard }\end{array}$ & 1970 & 20 & $\mathrm{Ep}$ & No & - & $\begin{array}{l}\text { Phenobarbitone } \\
\text { D.P.H. }\end{array}$ & - & Impaired \\
\hline Soulayrol \& Roger & 1970 & 100 & $\mathrm{Ep}$ & No & - & Ethosuximide & - & Impaired \\
\hline Ideström et al. & 1972 & 35 & Normal & No & 1 day & D.P.H. & 'Subtherapeutic' & Impaired \\
\hline $\begin{array}{l}\text { Reynolds \& } \\
\text { Travers }\end{array}$ & 1974 & 57 & $\mathrm{Ep}$ & No & - & $\begin{array}{l}\text { Phenobarbitone } \\
\text { D.P.H. }\end{array}$ & 'Therapeutic' & Impaired \\
\hline $\begin{array}{l}\text { Holdsworth \& } \\
\text { Whitmore }\end{array}$ & 1974 & 117 & Ep & No & 一 & $\begin{array}{l}\text { Phenobarbitone } \\
\text { Others not } \\
\text { specified }\end{array}$ & - & $\begin{array}{l}\text { None on educational } \\
\text { outcome }\end{array}$ \\
\hline Browne el al. & 1975 & 37 & Ep & No & 8 weeks & Ethosuximide & 'Therapeutic' & $\begin{array}{l}\text { No impairment } \\
\text { Improved in } 17\end{array}$ \\
\hline
\end{tabular}

In view of these observations of Lennox, and with the introduction of diphenylhydantoin (DPH) in 1938, and subsequently a succession of other anticonvulsant drugs, many studies of drug effects on mental processes may have been expected. However, while the acute effects of the new drugs were soon noted and recorded, chronic toxic side-effects, especially with regard to mental changes, seem to have received scant attention. In retrospect, it does not seem unlikely that such mental effects may occur. Thus epilepsy, more often than not, is a lifelong disorder. It requires continuous medication over a considerable number of years and treatment is often initiated in the early years of life, and hence may influence a developing nervous system. It is also known that chronic toxicity with anticonvulsants may permanently affect neural structures. Thus there are reports of persistent residual ataxia, attributed to cerebellar atrophy, and of peripheral neuropathy following anticonvulsant therapy (Reynolds, 1975a). The few studies of mental side-effects that have included psychometric techniques will be discussed, where possible, by considering individual drugs separately. A summary of these papers appears in Table 1.

\section{STUDIES OF INDIVIDUAL DRUGS}

\section{Bromides}

At one time the main therapy for epilepsy, bromides have ceased to be drugs of clinical importance in recent years and will therefore not be discussed. That these drugs were capable of adversely 
affecting the mental state is illustrated by the fact that bromism accounted for $4 \%$ of admissions to psychopathic hospitals in the early part of this century (Merritt, 1955).

\section{Phenobarbitone}

In the 1920s and 1930s the prevalent view was that phenobarbitone had no adverse effect on mental function, other than its soporific action, as is emphasized, for example, in the clinical reports of Grinker (1929) and Barnes \& Fetterman (1938).

A controlled trial by Somerfeld-Ziskind \& Ziskind (1940) in 100 patients also included a battery of six psychological tests. Although the control population of this study is inadequate, and the statistics are sparse, they state with confidence: 'This study indicates that phenobarbital in doses of $0.1 \mathrm{~g}$ two or three times a day can be given without resultant deterioration of intellect.' Wapner et al. (1962) examined 36 epileptic children between the ages of 8 and 12 and a control group of matched normal children, assessing their intelligence and learning abilities before and after six weeks of treatment with phenobarbitone. They found no statistical difference in the performance of the children at the two test periods. They interestingly report that initial performance on a $\mathrm{T} / \mathrm{sty}$ lus maze was superior in the control group, but the net gain in the two groups in this index during the period of the trial was in fact the same. In contrast to these negative findings, Tchicaloff \& Gaillard (1970) in a psychometric study of 20 epileptics found a correlation between dose of phenobarbitone and impaired performance on some subtests of the WAIS. They clearly implicate the drug as responsible for this deterioration. A one month study by Hutt et al. (1968) on normal adults also suggested that phenobarbitone impairs performance in certain psychological tests of perceptual-motor behaviour, i.e. key pressing, vigilance, verbal learning and speech rate, as will be discussed later in the section on anticonvulsant drug levels.

It is widely known and taught by paediatricians that phenobarbitone may precipitate or aggravate behaviour disorders or hyperkinetic syndromes in children, e.g. Ounsted (1955), but curiously we have been unable to trace any objective study of this phenomenon.

\section{Diphenylhydantoin $(D P H)$}

Many of the early clinical reports following the introduction of DPH in 1938 suggested a positive psychotropic effect of the drug leading to improved alertness, mood, behaviour and sociability. It seems to us likely that such effects resulted from improved seizure control and reduction of previously heavy doses of phenobarbitone. A direct psychotropic effect is not generally recognized now except in some parts of the United States where a new interest in treating some forms of psychiatric illness with the drug has emerged following its apparently successful use in a millionaire (e.g. Turner, 1967; Simopoulos et al., 1974).

It was soon recognized that acute toxic doses of DPH had adverse effects on the mental states of epileptics leading to a confusional state, sometimes referred to as delirium, encephalopathy or psychosis and associated with neurological signs of toxicity, especially nystagmus and ataxia. The early literature is reviewed by Finkelman \& Arieff (1942) who described four cases of their own, and the whole syndrome has been well reviewed by Roseman (1961). The very high blood levels of DPH associated with the acute confusional state are emphasized by Kutt et al. (1964).

In relation to possible chronic effects Booker et al. (1967) employed a battery of psychological tests in a controlled study in 17 normal students who were given $100 \mathrm{mg}$ of DPH three times daily or a placebo for six days. No consistent effects attributable to the drug were found.

Rosen (1968) comments that decreased intellectual performance may be a complication of longterm DPH therapy in some epileptics in view of his observations in 20 such patients in whom school work performance improved rapidly when the drug was discontinued for various reasons. The improvement was associated with corresponding changes in WAIS, Bender Gestalt and other tests of intellectual and perceptual performance, but few details were given.

Ideström et al. (1972) in a 24-hour study of normal students found some correlation between serum 
DPH levels and some measures of impairment of concentration and psychomotor performance, as will be discussed later in the section on anticonvulsant serum levels.

\section{Ethosuximide}

Using a test/retest situation the effects of this drug were assessed in 25 children with petit mal by Guey et al. (1967). At the start of the experiment the children were receiving other anticonvulsants which were continued. The children were then reassessed after a period of several months on ethosuximide. The authors claimed that this drug caused psychic disturbance which affected both the intellectual and affective spheres, the former mainly showing as memory and speech disturbances. These effects were seen most markedly in older patients and in those who were receiving higher doses of the drug. This study, however, must be interpreted with caution for several reasons: (1) 15 of their 25 patients were mentally retarded; (2) the patients were receiving other drugs at the time of the trial; (3) they did not include a control group for comparison. The importance of proper controls in such a study as this is paramount, especially as it has been shown that EEG spike/wave activity of petit mal epilepsy may be correlated with impaired visual-motor performance (Goode et al., 1970). An important feature that the study again emphasizes, however, is the necessity to explore as many individual components of intellectual functioning as possible. Thus if an overall assessment is taken such as, for example, full scale IQ, verbal IQ, or performance IQ, significant differences may not be, and in fact were not, obtained. More subtle subtests, however, may yield significant results and in this investigation the subtests in which significant differences emerged were comprehension, memory and spatio-temporal perceptual difficulties. In a more extended study of 100 patients with petit mal epilepsy receiving ethosuximide, Soulayrol \& Roger (1970) confirmed their earlier findings and conclude that intellectual efficiency falls significantly in most of the children treated with the drug.

However, in a recent controlled study of 37 epileptic children with petit mal, Browne et al. (1975) reported no deleterious effects of 'therapeutic' blood levels of ethosuximide on psychometric performance over a period of 8 weeks. Furthermore, the performance of 17 of these patients improved, probably associated with the very good control of seizures achieved. They discuss several possible explanations for the discrepancy between their own and Guey et al.'s findings. Earlier, Smith et al. (1968) reported beneficial effects of the drug on verbal and full scale IQ scores, but not motor performance or personality, in non-epileptic children with learning disorders and 14 and 6/sec positive spikes on the EEG.

\section{Carbamazepine}

Adverse effects on the mental state have rarely been reported with this relatively newer anticonvulsant (Reynolds, 1975b). Indeed, great interest has centred around the possibility that this drug has direct psychotropic properties, especially in view of its structural relationship to tricyclic antidepressants. The conflicting literature on this aspect has been reviewed by Dalby (1975). In our opinion the case for a direct psychotropic effect is unproven and may in part be based on a failure to recognize the adverse effects of the older anticonvulsants on mental processes. Most of the reports claiming such properties indicate that phenobarbitone and/or DPH were gradually reduced or stopped and the type of mental change attributed to carbamazepine is remarkably similar to the effects of such withdrawal, i.e. improved alertness, drive, concentration, mood and sociability, with reduced irritability. We are unaware of any reports of such benefit when carbamazepine has been used as the first or only drug in the treatment of epilepsy, nor during the treatment of trigeminal neuralgia with the same drug.

\section{STUDIES NOT SEPARATING DRUGS}

Loveland et al. (1957) in a extensive study of 26 epileptic patients on anticonvulsant drugs, assessed their psychological abilities over a period of three months in a test/retest situation. From a battery of psychometric tests they were able to derive 2000 separate items on which statistical analyses were possible. Only 44 of these were significant and their general conclusion was that the drugs admini- 
stered had little or no effect on their total adjustment to their environment. However, there was no control for the dose of the various drugs given. Furthermore, the majority of their patients were already receiving their anticonvulsants for some years prior to the study and it is perhaps not surprising that no decline in performance was seen over a subsequent three month period. Only five patients were not on medication at the initial testing. On retesting this group improved less in their delayed recall than in their matched controls.

Royo \& Martin (1959) described three epileptic children who were given full psychological testing while receiving anticonvulsant therapy with multiple drugs. They suggest that anticonvulsants not only lower intellectual efficiency in general, but have a particularly impressive effect on visuoperceptive and visuo-spatial discrimination. These effects they considered to be due to ill-balanced therapy'.

Chaudhry \& Pond (1961) in their controlled study of 28 epileptic children who showed intellectual deterioration (as measured by decline in IQ scores) found no evidence to implicate anticonvulsants as a cause for this and suggested that the deterioration was related to seizure frequency. However, drug intake was assessed using a rating scale which assumed that $60 \mathrm{mg}$ of phenobarbitone was equivalent to $100 \mathrm{mg}$ of DPH and $0.5 \mathrm{~g}$ of primidone.

In contrast, Tchicaloff \& Gaillard (1970) reported that phenobarbitone and DPH together do impair mental function, and on tests of visuo-spatial performance significant cumulative effects of the drugs were observable. Kerfriden (1970) supported their conclusions and stated that anticonvulsant medication seems to be an obstacle to learning in the epileptic child.

Holdsworth \& Whitmore (1974), on the other hand, in a study of 117 epileptic children at ordinary schools, found no difference in educational outcome according to whether or not phenobarbitone was being prescribed. No indication is given of the dosages employed or what other drugs were being taken. Educational performance was assessed on questionnaires completed from interviews with teachers, without specific testing of the children.

\section{STUDIES INCLUDING SERUM ANTICONVULSANT LEVELS}

A significant factor in stimulating interest in the effects of anticonvulsants on mental processes has been the development of techniques for the measurement of serum anticonvulsant levels. Conventionally, the drugs have been administered by increasing the dose until seizures are controlled or until toxic signs are produced, when the dose is marginally reduced. The first sign of toxicity is usually thought to be nystagmus, and some have even considered it desirable that nystagmus should be present in a patient receiving anticonvulsant medication (Haerer \& Grace, 1969). With the ability to detect anticonvulsants in the serum, 'therapeutic' and toxic levels have recentlý been defined for several anticonvulsants (see Woodbury et al., 1972). It is now apparent that intoxication is better correlated with serum level than with daily dosage. Thus, for example, side effects of DPH were reported as being absent with serum levels below $15 \mu \mathrm{g} / \mathrm{ml}$, mild in $15 \%$ of patients with serum levels between 15 and $30 \mu \mathrm{g} / \mathrm{ml}$, and severe in $50 \%$ of patients with levels of over $30 \mu \mathrm{g} / \mathrm{ml}$ (Buchthal \& Svensmark, 1971). Kutt et al. (1964) reported a close correlation between individual signs of toxicity and serum levels of DPH, nystagmus occurring in the range of $14-25 \mu \mathrm{g} / \mathrm{ml}$, ataxia between 30 and $40 \mu \mathrm{g} / \mathrm{ml}$ and mental confusion only above $40 \mu \mathrm{g} / \mathrm{ml}$. Other evidence, however, does not reveal such a precise relationship. Individual variation is apparent and not all patients exhibit the classical signs of toxicity (Reynolds, 1970).

\section{Subacute or chronic diphenylhydantoin encephalopathy}

Although a confusional state, sometimes referred to as encephalopathy, delirium or psychosis has long been recognized as an acute toxic effect of DPH associated with other clear neurological evidence of toxicity such as nystagmus and ataxia (Finkelman \& Arieff, 1942; Kutt et al., 1964; Glaser, 1972), the measurement of serum levels of the drug has recently revealed that a subacute or chronic reversible impairment of intellectual function, awareness and mood due to the drug may easily be overlooked due to the absence of the classical signs of toxicity. 
Husby (1963), who measured serial blood levels of the drug in 151 patients over a period of 5-18 months, noted the insidious development of depression in three and dementia in two, associated with serum concentrations between 34 and $58 \mu \mathrm{g} / \mathrm{ml}$. Some had mild disturbance of gait but nystagmus was not recorded and the mental symptoms disappeared on reduction of therapy. Frantzen et al. (1967) and Reynolds (1970) also noted a much broader concept of the psychiatric and neurological complications of insidious DPH toxicity as a result of blood level measurements. Intellectual deterioration, depression and aggravation of behaviour disorders were included in the spectrum encountered. Impairment of drive and initiative, psychomotor slowing and lowering of mood were particularly common according to Reynolds (1970).

Examples of this encephalopathy have been stressed particularly in children, in whom nystagmus and ataxia may not occur, especially in the presence of pre-existing brain damage or mental retardation, and in whom further deterioration in intellectual function may be overlooked, or mistakenly regarded as part of an underlying progressive neurological disease which may be responsible for the fits (Patel \& Crichton, 1968; Rosen, 1968; Logan \& Freeman, 1969; Weiss et al., 1969; Prensky et al., 1971). Further examples in adults have been reported by Perlo and Schwab (1969) and Reynolds \& Travers (1974). Sometimes the encephalopathy may be associated with unusual neurological signs including involuntary movements (Kooiker \& Sumi, 1974; McLellan \& Swash, 1974) which may further perpetuate a vain search for underlying neurological disease. A modest rise of CSF protein may be found (Rawson, 1968). Although blood levels of the drug are nearly always in the toxic range, this syndrome may occasionally occur with 'therapeutic' levels (Glaser, 1972).

The above evidence suggests that serious effects on mental function may occasionally occur with toxic levels of DPH in the absence of more classical signs of toxicity. Delay in recognition of such toxicity may occur unless serum anticonvulsant levels are measured. Other, more recent evidence suggests the possibility that mental symptoms, albeit of a more subtle kind, may occur with blood levels below the generally recognized toxic range, especially if therapy is prolonged. Reynolds \& Travers (1974) studied a group of 57 outpatient epileptics on chronic therapy with DPH and phenobarbitone. Intellectual deterioration, psychiatric illness or personality change and psychomotor slowing were recorded as present or absent on the basis of clinical assessment and (in $50 \%$ ) psychometric studies. After excluding those patients with overt drug toxicity, gross cerebral lesions, or mental symptoms preceding the onset of epilepsy, those patients with mental symptoms were found to have significantly higher concentrations of both phenobarbitone and DPH than patients without such mental changes (with the single exception of phenobarbitone in relation to psychomotor slowing where the trend was similar but not statistically significant). That this was not merely a reflexion of more frequent seizures, and hence higher dosage of drugs, was made less likely when similar differences were noted in patients with infrequent seizures (less than one a month). In the groups with mental changes the mean serum levels of both DPH and phenobarbitone were within the range generally regarded as 'therapeutic' (i.e. $10-20 \mu \mathrm{g} / \mathrm{ml}$ for DPH; 15-35 $\mu \mathrm{g} / \mathrm{ml}$ for phenobarbitone), although a wide scatter was also encountered. The implication is that in some patients drug effects on mental processes may occur in patients not only in the absence of physical signs of toxicity but also with serum levels not generally regarded as toxic. It is emphasized that considerable individual variation in tolerance to the mental effects of the drugs exists and that apart from the level of the drug in the serum the duration of therapy may be important.

Other evidence that mental effects may occur at relatively low or 'therapeutic' levels is to be found in the studies of Hutt et al. (1968) and Ideström et al. (1972) in normal volunteers. In four normal adults treated with phenobarbitone for up to one month the former authors found correlations between blood levels of the drug (which reached 'therapeutic' levels) and impairment of various measures of perceptual-motor performance, including key-pressing, vigilance, verbal learning and speech rate. Some tests, e.g. the Gibson spiral test, were impaired only at high levels ( $>25 \mu \mathrm{g}$ ) $\mathrm{ml}$ ) of the drug, but others, e.g. key-pressing and verbal learning, were increasingly impaired in proportion to the blood level. They reinforce the point that a broad spectrum of tests must be sampled before a drug can be said to have significant effects and that the difficulty and duration of the task as well as social constraints are important in assessing performance. For example, in a 30-minute 
test for vigilance, no deterioration was detected in the first 10 minutes, but thereafter decline in performance was rapid. Similar studies in larger numbers of subjects and in epileptic patients would seem to be indicated.

Ideström et al. administered only three doses of DPH to normal students and at 24 hours found some correlation between blood levels of the drug, which were 'subtherapeutic', and some measures or ratings of concentration and psychomotor performance, including reaction time and critical flicker fusion.

\section{METABOLIC EFFECTS OF ANTICONVULSANTS RELATED TO MENTAL SYMPTOMS}

Another factor which has focused attention on the possible adverse effect of anticonvulsants on mental processes has been the increasing recognition in recent years of several metabolic complications of chronic therapy with these drugs and especially their impact on folate metabolism. This aspect has been reviewed in detail elsewhere (Reynolds, 1975a) and will only be summarized here. Although anticonvulsant megaloblastic anaemia is rare, evidence of disturbed folate metabolism can be detected in the majority of drug-treated epileptic patients as reflected by a fall in serum, red cell and, of particular importance, CSF folate levels. The three major anticonvulsants, DPH, phenobarbitone and primidone have been incriminated and there is an inverse relationship between anticonvulsant and folate levels in serum and CSF, but the mechanism of this effect of the drugs is uncertain. Epileptic patients with mental illness have, as a group (but not in every case), significantly lower folate levels (and higher drug levels - see above) than epileptic patients with normal mental states. It is likely that the severity and duration of the deficiency as well as other predisposing factors (e.g. genetic, brain damage, psychosocial) determine whether or not mental changes occur. No specific diagnosis has been incriminated but patients with dementia have the lowest folate values of all. Evidence that treatment with folic acid may improve the mental state (and aggravate seizures) in some patients has been conflicting, but the position has been complicated by a considerable blood-brain barrier mechanism for the vitamin. The type of mental change reported with vitamin therapy (increased alertness, drive, concentration and mood) is similar to that seen following withdrawal of anticonvulsant therapy. There is also evidence that severe folate deficiency in nonepileptic patients may occasionally produce mental and other neurological symptoms.

Evidence that anticonvulsants influence the metabolism of indoleamines and catecholamines, leading to increase in CSF 5HIAA and HVA has recently been demonstrated in epileptic patients (Chadwick et al., 1975). The importance of monoamines in mental function is widely recognized and the possible relevance of these changes, and their relationship, if any, to the disturbed folate metabolism in epileptic patients is currently being investigated (Reynolds et al., 1975).

Of several other metabolic consequences of anticonvulsant therapy none have so far been linked with mental changes, although it would not be surprising if such evidence emerged. For example, there is equivocal evidence that the drugs may affect the metabolism of vitamin $B_{6}$; and the many possible metabolic ramifications of the liver enzyme inducing properties of the drugs have only recently been appreciated.

\section{EPILEPSY AND PSYCHOSIS}

The subject of the relationship between epilepsy and schizophrenia-like psychoses has been reviewed by Davison \& Bagley (1969) and only brief reference will be made to it here, because of the possible influence of anticonvulsant therapy in the genesis of the psychosis in some cases. It has been variously suggested that epilepsy and schizophrenia are biologically antagonistic (Meduna, 1937), have an increased association (Slater et al., 1963) or occur together by chance. Reynolds (1968) has suggested that if allowance is made for the precipitation of psychosis in epileptic patients by anticonvulsant drugs and the precipitation of fits in schizophrenia by phenothiazines then the balance of evidence may indeed favour Meduna's hypothesis, at least in some cases. There are many reports of psychosis occurring in epileptic patients at a time when seizures are under much better control (see Reynolds, 1968; Roger et al., 1968; Wolf, 1973), sometimes associated with so-called 'forced normalization' 
of the EEG (Landolt, 1958), although undoubtedly this does not apply to all patients. There is also some evidence that a similar inverse relationship occurs between seizure frequency and depression in some patients (Betts, 1974). The role of anticonvulsant drugs in this phenomenon deserves further investigation as it has implications for an understanding of the relationship between epilepsy and mental illness and also the mechanism of action of ECT (seizures) in psychiatric illness.

\section{SUMMARY AND CONCLUSION}

Many, but not all, of the studies and case reports that have been reviewed in this paper suggest that anticonvulsant medication may have an adverse effect on the mental processes of epileptic patients, quite apart from any indirectly beneficial effects from controlling seizures. Some evidence suggests that subtle mental changes may occur in patients even with blood levels of the drugs that are within or below presently accepted 'therapeutic' ranges, especially if duration of therapy is taken into account. Other evidence suggests that in some patients overt psychiatric illness or intellectual deterioration may occur, especially if blood levels are high, and that this may easily be overlooked if other signs of toxicity are absent, as may occur. It is apparent from Table 1 that there is a dearth of well-controlled studies which include adequate numbers of patients, studied for a prolonged period of time applying a broad spectrum of objective psychological measurements, and including blood level estimates of the various drugs. It is important that seizure control is not achieved at the expense of deteriorating social and psychological functioning of the patients, and that a proper balance is struck between the benefits and hazards of therapy. It is clearly desirable, therefore, both for the patient and the physician, that the effects of anticonvulsants on mental processes should be better defined. Patients who may be particularly susceptible to such effects need to be identified. Comparative tests are needed between the conventional anticonvulsant drugs such as phenobarbitone, DPH and primidone and newer anticonvulsant drugs. Likewise the effects of a single drug as opposed to multiple drugs needs assessment.

In view of the delay in recognizing so many of the chronic effects of anticonvulsants (Reynolds, $1975 a$ ) it is germane to consider whether other drugs utilized in neuropsychiatric illness may have long-term adverse effects on mental function. Thus psychotropic drugs, in the same way as anticonvulsants, may be used for long periods of time and tend to be liberally prescribed. It is already known that chronic phenothiazine therapy may result in permanent dyskinesia and it would not surprise us if adverse mental effects (in addition to the beneficial ones) emerged with the long-term use of these and other psychotropic drugs (see, for example, Pollack, 1970).

Over 30 years ago Lennox (1942), referring to the effects of medication on the mental state of epileptic patients, stated 'strangely enough, properly controlled observations of the side effects of drug therapy seem to be lacking. . . the careful study of the effect of anticonvulsant drugs on the intellectual processes of normal and epileptic persons is long overdue'. These comments are still pertinent today. It is hoped that this review will stimulate more awareness of and research into this neglected problem.

M. R. TRIMBLE

E. H. REYNOLDS

\section{REFERENCES}

Barnes, M. R. \& Fetterman, J. N. (1938). Mentality of dispensary epileptic patients. Archives of Neurology and Psychiatry 40, 903-910.

Betts, T. A. (1974). A follow-up study of a cohort of patients with epilepsy admitted to psychiatric care in an English city. In P. Harris \& C. Maudsley (eds), Epilepsy; Proceedings of the Hans Berger Centenary Symposium, pp. 326336. Churchill Livingstone: Edinburgh.

Booker, H. E., Matthews, C. G. \& Slaby, A. (1967). Effects of diphenylhydantoin on selected physiological-psychological measures in normal adults. Neurology 17, 949-951.

Browne, T. R., Dreifuss, F. E., Dyken, P. R., Goode, D. J., Penry, J. K., Porter, R. J., White, B. G. \& White, P. T.
(1975). Ethosuximide (zarontin) in the treatment of absence (petit mal) seizures. Neurology 25, 515-525.

Buchthal, F. \& Svensmark, O. (1971). Serum concentrations of diphenylhydantoin and phenobarbital and their relation to therapeutic and toxic effects. Psychiatria, Neurologia et Neurochirurgia 74, 117-136.

Chadwick, D., Jenner, P. \& Reynolds, E. H. (1975). Amines, anticonvulsants and epilepsy. Lancet $\mathrm{i}, 473-476$.

Chaudhry, M. R. \& Pond, D. A. (1961). Mental deterioration in epileptic children. Journal of Neurology, Neurosurgery and Psychiatry 24, 213-219.

Dalby, M. A. (1975). Carbamazepine: behavioural effects. In J. K. Penry (ed.), Complex Partial Seizures and their Treatment, pp. 331-344. Raven Press: New York. 
Davison, K. \& Bagley, C. (1969). Schizophrenia-like psychoses associated with organic disorders of the nervous system. In Current Problems in Psychiatry. British Journal of Psychiatry, Special Publication Number 4.

Finkelman, I. \& Arieff, A. J. (1942). Untoward effects of phenytoin sodium in epilepsy. Journal of the American Medical Association 118, 1209-1212.

Fox, J. T. (1924). Response of epileptic children to mental and educational tests. British Journal of Medical Psycho$\log y$ 4, 235-248.

Frantzen, E., Hansen, J. M., Hansen, O. E. \& Kristensen, M. (1967). Phenytoin (dilantin) intoxication. Acta Neurologica Scandinavica 43, 440-446.

Glaser, G. H. (1972). Diphenylhydantoin toxicity. In D. M. Woodbury, J. K. Penry \& R. P. Schmidt (eds), Antiepilepric Drugs, pp. 219-226. Raven Press: New York.

Goode, D. J., Penry, J. K. \& Dreifuss, F. E. (1970). Effect of paroxysmal spike-wave on continuous visual motor performance. Epilepsia 11, 241-254.

Gowers, W. R. (1885). Epilepsy and Other Chronic Convulsive Diseases: Their Causes, Symptoms and Treatment. William Wood: London.

Grinker, R. R. (1929). The proper use of phenobarbital in the treatment of the epilepsies. Journal of the American Medical Association 93, 1218-1219.

Guerrant, J., Anderson, W. W., Fischer, A., Weinstein, M. R., Jaros, R. M. \& Deskins, A. (1962). Personality in Epilepsy. Thomas: Springfield.

Guey, J., Charles, C., Coquery, C., Roger, J. \& Soulayrol, R: (1967). Study of psychological effects of ethosuccimide (zarontin) on 25 children suffering from petit mal epilepsy. Epilepsia 8, 129-141.

Haerer, A. F. \& Grace, J. B. (1969). Studies of anticonvulsant levels in epileptics. Acta Neurologica Scandinavica 45, 18-31.

Holdsworth, L. \& Whitmore, K. (1974). A study of children with epilepsy attending ordinary schools. Developmental Medicine and Child Neurology 16, 746-758.

Husby, J. (1963). Delayed toxicity and serum concentrations of phenytoin. Danish Medical Bulletin 10, 236-239.

Hutt, S. J., Jackson, P. M., Belsham, A. B. \& Higgins, G (1968). Perceptual-motor behaviour in relation to blood phenobarbitone level. Developmental Medicine and Child Neurology 10, 626-632.

Ideström, C. M., Schalling, D., Carlquist, U. \& Sjöquist, F. (1972). Behavioural and psychophysiological studies: acute effects of diphenylhydantoin in relation to plasma levels. Psychological Medicine 2, 111-120.

Kerfriden, P. (1970). Effets psychiques de favorables des médications anticomitiales. Revue de Neuropsychiatrie Infantile 18, 605-609.

Kooiker, J. C. \& Sumi, S. M. (1974). Movement disorder as a manifestation of diphenylhydantoin intoxication. Neurology 24, 68-71.

Kutt, H., Winters, W., Kokenger, R. \& McDowell, F. (1964). Diphenylhydantoin metabolism, blood levels and toxicity. Archives of Neurology 11, 642-648.

Landolt, H. (1958). Serial electroencephalographic investigations during psychotic episodes in epileptic patients and during schizophrenic attacks. In A. M. Lorentz de Haas (ed.), Lecrures on Epilepsy, pp. 91-133. Elsevier: Amsterdam.

Lennox, W. G. (1942). Brain injury, drugs and environment as causes of mental decay in epilepsy. American Journal of Psychiatry 99, 174-180.

Lennox, W. G. \& Lennox, M. A. (1960). Epilepsy and Related Disorders. Little, Brown: Boston.

Logan, W. J. \& Freeman, J. M. (1969). Pseudodegenerative disease due to diphenylhydantoin intoxication. Archives of Neurology 21, 631-637.

Loveland, N., Smith, B. \& Forster, F. M. (1957). Mental and emotional changes in epileptic patients on continuous anticonvulsant medication. Neurology 7, 856-865.
McLellan, D. L. \& Swash, M. (1974). Choreoathetosis and encephalopathy induced by phenytoin. British Medical Journal ii, 204-205.

Meduna, L. (1937). Die Konvulsionstherapie der Schizophrenie. Marhold: Halle.

Merritt, H. H. (1955). A Textbook of Neurology. Lea and Febiger: Philadelphia.

Ounsted, C. (1955). The hyperkinetic syndrome in epileptic children. Lancet ii, 303-311.

Patel, H. \& Crichton, J. U. (1968). The neurologic hazards of diphenylhydantoin in childhood. Journal of Pediatrics 73, 676-684.

Perlo, V.P. \& Schwab, R. S. (1969). Unrecognized dilantin intoxication. In S. Locke (ed.), Modern Neurology, pp. 589597. Little, Brown: Boston.

Pollack, M. (1970). Chlorpromazine and CNS changes in man. In W. L. Smith \& G. A. Ulett (eds), Drtigs and Cerebral Function. Thomas: Springfield.

Prensky, A. L., De Vivo, D. C. \& Palkes, H. (1971). Severe bradykinesia as a manifestation of toxicity to antiepileptic medications. Journal of Pediatrics 78, 700-704.

Rawson, M. D. (1968). Diphenylhydantoin intoxication and cerebrospinal fluid protein. Neurology 18, 1009-1011.

Reynolds, E. H. (1968). Epilepsy and schizophrenia: relationship and biochemistry. Lancet i, 398-401.

Reynolds, E. H. (1970). Iatrogenic disorders in epilepsy. In D. Williams (ed.), Modern Trends in Neurology, no. 5, pp. 271-286. Butterworths: London.

Reynolds, E. H. \& Travers, R. D. (1974). Serum anticonvulsant concentrations in epileptic patients with mental symptoms. British Journal of Psychiarry 124, 440-445.

Reynolds, E. H. (1975a). Chronic antiepileptic toxicity: a review. Epilepsia 16, 319-352.

Reynolds, E. H. $(1975 b)$. Carbamazepine neurotoxicity. In J. K. Penry \& D. Daly (eds), Complex Partial Selzures and their Treatment, pp. 345-353. Raven Press: New York.

Reynolds, E. H., Chadwick, D., Jenner, P. \& Chanarin, I. (1975). Folate and monoamine metabolism in epilepsy. Journal of Neurological Sciences 26, 605-615.

Roger, J., Grangeon, H., Guey, J. \& Lob, H. (1968). Incidences psychiatriques et physiologiques du traitement par l'éthosuccimide chez les épileptiques. L'encéphale 5, 407-438.

Roseman, E. (1961). Dilantin toxicity. Neurology 11, 912-921.

Rosen, J. A. (1968). Dilantin dementia. Transactions of the American Neurological Association 93, 273.

Royo, D. \& Martin, F. (1959). Standardized psychometrical tests applied to the analysis of the effect of anticonvulsant medication on the intellectual proficiency of young epileptics. Epilepsia 1, 189-207.

Simopoulos, A. M., Pinto, A., Uhlenhuth, E. H., McGee, J. J. \& De Rosa, E. R. (1974). Diphenylhydantoin effectiveness in the treatment of chronic schizophrenics. Archives of General Psychiatry 30, 106-111.

Slater, E., Beard, A. W. \& Glithero, E. (1963). The schizophrenia-like psychoses of epilepsy. British Journal of Psychiatry 109, 95-150.

Smith, W. L., Philipus, M. J. \& Guard, H. L. (1968). Psychometric study of children with learning problems and 14-16 positive spike EEG patterns, treated with ethosuccimide (zarontin) and placebo. Archives of Diseases of Childhood 43, 616-619.

Somerfeld-Ziskind, E. \& Ziskind, E. (1940). Effect of phenobarbital on the mentality of epileptic patients, Archives of Neurology and Psychiatry 43, 70-79.

Soulayrol, R. \& Roger, J. (1970). Effets psychiatriques défavorables des médications anti-épileptiques. Revue de Neuropsychiatrie infantile 18, 591-598.

Temkin, O. (1971). The Falling Sickness. Johns Hopkins: Baltimore.

Tchicaloff, M. \& Gaillard, F. (1970). Quelques effets indésirables des médicaments anti-épileptiques sur les 
rendements intellectuels. Revue de Neuropsychiatrie infantile 18, 599-602.

Turner, W. J. (1967). Therapeutic use of diphenylhydantoin in neuroses. International Journal of Neuropsychiatry 3, 94-105.

Weiss, C. F., Heffelfinger, J. C. \& Buchanan, R. A. (1969) Serial dilantin levels in mentally retarded children. American Journal of Mental Deficiency 73, 826-830.
Wapner, I., Thurston, D. L. \& Holowach, J. (1962). Phenobarbital: its effect on learning in epileptic children. Journal of the American Medical Association 182, 937.

Wolf, P. (1973). Zur Pathophysiologie epileptischer Psychosen. In H. Penin (ed), Psychische Srörungen bei Epilepsie, pp. 51-65. F. K. Schattauer Verlag: Stuttgart.

Woodbury, D. M., Penry, J. K. \& Schmidt, R. P. (eds), (1972). Antiepileptic Drugs. Raven Press: New York

Reprint requests to:

Department of Neurology,

Institute of Psychiatry,

De Crespigny Park,

Denmark Hill,

London SE5 8AF 